Original article

\title{
Tetraploid Carrizo citrange rootstock (Citrus sinensis Osb. $\times$ Poncirus trifoliata L. Raf.) enhances natural chilling stress tolerance of common clementine (Citrus clementina Hort. ex Tan)
}

\author{
Julie Oustric ${ }^{\mathrm{a}}$, Raphaël Morillon ${ }^{\mathrm{b}}$, François Luro ${ }^{\mathrm{c}}$, Stéphane Herbette ${ }^{\mathrm{d}}$, Radia Lourkisti ${ }^{\mathrm{a}}$, \\ Jean Giannettini ${ }^{\mathrm{a}}$, Liliane Berti ${ }^{\mathrm{a}}$, Jérémie Santini ${ }^{\mathrm{a}, *}$ \\ ${ }^{\text {a }}$ CNRS, UMR 6134 SPE, Laboratoire Biochimie and Biologie Moléculaire du Végétal, 20250 Corte, France \\ b Equipe "Amélioration des Plantes à Multiplication Végétative", UMR AGAP, Département BIOS, CIRAD, Station de Roujol, 97170 Petit-Bourg, Guadeloupe, France \\ ' UMR AGAP Corse, station INRA/CIRAD, 20230 San Giuliano, France \\ d UCA, INRA, PIAF, 63000 Clermont-Ferrand, France
}

\section{A R T I C L E I N F O}

\section{Keywords:}

Antioxidant

Citrus

Cold stress

Photosynthesis

Polyploidy

Rootstock

\begin{abstract}
A B S T R A C T
Low temperatures can disturb the development, growth and geographic distribution of plants, particularly coldsensitive plants in the Mediterranean area, where temperatures can reach seasonally low levels. In citrus crops, scion/rootstock combinations are used to improve fruit production and quality, and increase tolerance to biotic and abiotic stresses. In the last decade, several studies have shown that tetraploid citrus seedlings or rootstocks are more tolerant to abiotic stress than their respective diploid. The objective of this study was to test whether the use of tetraploid rootstocks can improve the chilling tolerance of the scion. We compared physiological and biochemical responses to low seasonal temperatures of common Clementine (Citrus sinensis Osb. $\times$ Poncirus trifoliata L. Raf.) grafted on diploid and tetraploid Carrizo citrange rootstocks, named $\mathrm{C} / 2 \mathrm{xCC}$ and $\mathrm{C} / 4 \mathrm{xCC}$, respectively. During the coldest months, $\mathrm{C} / 4 \mathrm{xCC}$ showed a smaller decrease in net photosynthesis $(\mathrm{Pn})$, stomatal conductance $\left(G_{\mathrm{s}}\right)$, chlorophyll fluorescence $\left(F_{\mathrm{v}} / F_{\mathrm{m}}\right)$, and starch levels, and lower levels of malondialdehyde and electrolyte leakage than C/2xCC. Specific activities of catalase (CAT), ascorbate peroxidase (APX) and dehydroascorbate reductase (DHAR) were higher in $\mathrm{C} / 4 \mathrm{xCC}$ during the cold period, whereas chlorophyll, proline, ascorbate and hydrogen peroxide $\left(\mathrm{H}_{2} \mathrm{O}_{2}\right)$ levels and superoxide dismutase (SOD) activity did not vary significantly between $\mathrm{C} / 4 \mathrm{xCC}$ and $\mathrm{C} / 2 \mathrm{xCC}$ throughout the study period. Taken together, these results demonstrate that tetraploid Carrizo citrange rootstock improves the chilling tolerance of common clementine (scion) thanks to a part of the antioxidant system.
\end{abstract}

\section{Introduction}

Polyploidy is a common biological phenomenon and a major force of plant evolution (Chen, 2007; Soltis and Soltis, 2009). In nature, $50-70 \%$ of angiosperms have undergone at least one episode of polyploidization (Masterson, 1994). In citrus, tetraploid can be divided into two categories - doubled diploid or allotetraploid (Stebbins, 1947) - resulting from either somatic chromosome doubling or sexual reproduction via $2 \mathrm{n}$ gametes, respectively. Doubled diploid citrus genotypes arise from somatic chromosome doubling and from intraspecific hybridization or self-fertilization through $2 \mathrm{n}$ gametes, with the subgenomes in doubled diploid thus being considered identical (Aleza et al., 2011). Allotetraploids citrus inherited subgenomes from two different parents after interspecific hybridization. Tetraploidization may lead to specific genome expression changes that can in turn induce phenotypic changes that trigger an increase in productivity and

Abbreviations: ABA, abscisic acid; Asa, reduced ascorbate; APX, ascorbate peroxidase; CAT, catalase; $\mathrm{CBF}$, C-repeat-binding factor; $\mathrm{CO}_{2}$, carbon dioxide concentration; DHA, oxidized

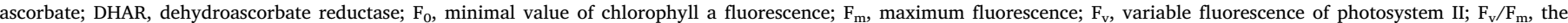

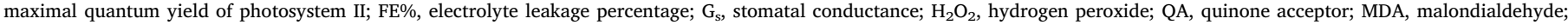

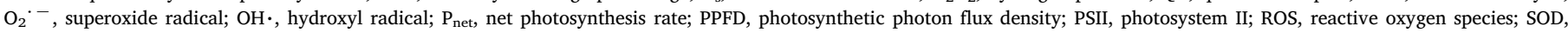

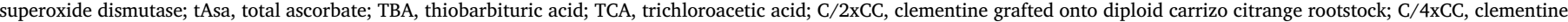
grafted onto tetraploid Carrizo citrange rootstock

* Corresponding author.

E-mail addresses: oustric-filippi_j@univ-corse.fr (J. Oustric), raphael.morillon@cirad.fr (R. Morillon), luro@corse.inra.fr (F. Luro), lourkisti_r@univ-corse.fr (R. Lourkisti), gianetti@univ-corse.fr (J. Giannettini), berti@univ-corse.fr (L. Berti), jeremie.santini@univ-corse.fr (J. Santini). 
efficiency, especially by enhancing stress tolerance (Tan et al., 2015). Polyploid species are more common in extreme environments, with low temperatures, high radiation, low fertility soils and dry conditions (Brochmann et al., 2004; Ehrenforfer, 1980; Levin, 1983). Based on several reports, the use of tetraploid genotypes is an alternative way to improve stress tolerance in many crops (Saleh et al., 2008; Meng et al., 2012; Tan et al., 2015; Ruiz et al., 2016a,b,c). In a previous study, we showed that tetraploid Rangpur lime (Citrus limonia Osbeck) rootstock improved the water deficit tolerance of Valencia scion compared to the use of diploid Rangpur lime rootstock grafted with Valencia scion (Allario et al., 2013).

Rootstock/scion combinations are frequently employed in the citrus industry to improve fruit production and quality, and the tolerance to biotic and abiotic stresses. The rootstocks are selected for root traits linked to resistance to pests and pathogens from the soil but also to various abiotic stresses such as salinity, drought, floods and cold. Roots subjected to cold have decreased water absorption due to increased root hydraulic resistance (Kramer, 1940) and decreased membrane permeability (McElhaney et al., 1973). This results in decreased nutrient and water absorption causing a disruption of plant growth and development (Ahn et al., 1999). Usually, citrus rootstocks are diploid with a basic chromosome number $x=9$ (Krug, 1943). Citrus rootstocks are propagated by polyembryonic seeds since citrus species are partially apomictic. Spontaneous doubled diploid $(4 \times)$ seedlings may arise from chromosome set doubling of nucellar cells (maternal tissue) (Cameron and Frost, 1968).

Carrizo citrange (Citrus sinensis Osb. $x$ Poncirus trifoliata L. Raf.) and its parent Poncirus trifoliata are two rootstocks classically used in Corsica. When grown as seedlings, these genotypes have deciduous leaves and undergo winter dormancy. In Poncirus trifoliata, this marked difference was probably acquired during the evolutionary process in northeastern Asia when the trees were exposed to cold temperatures (Ziegler and Wolfe, 2017). However, when grafted, these cultivars are no longer deciduous and their cold tolerance is much more limited, although the use of Poncirus trifoliata and Carrizo citrange rootstock is still one of the most effective ways to boost cold tolerance. However, little is known regarding the mechanisms that allow the rootstock to improve the scion's cold tolerance.

When plants are exposed to cold temperatures, profound changes in gene expression are observed. The C-repeat-binding factor (CBFs) pathway is known to play a very important role in the response to cold stress (Chan et al., 2016). Huang et al. (2015) recently showed that, under cold conditions, ICE1 (inducer of CBF expression 1) of Poncirus trifoliata modulates polyamine levels through interactions with arginine decarboxylase. This leads to lower hydrogen peroxide $\left(\mathrm{H}_{2} \mathrm{O}_{2}\right)$ and superoxide radical $\left(\mathrm{O}_{2}{ }^{-}{ }^{-}\right)$contents, and higher activity of antioxidant enzymes, such as superoxide dismutase and catalase. Thus, it is likely that Carrizo citrange inherited this capacity to better tolerate cold from its Poncirus trifoliata parent. Carrizo citrange rootstock is also widely used since it is tolerant to Citrus Tristeza Virus and flooding. In addition, it promotes good fruit productivity and quality (PérezClemente et al., 2012).

In the Mediterranean region, the climate is dry and hot during the summer and relatively cold during the winter. Regions such as Corsica, which is the most northern citrus growing area, can sometimes have relatively low temperatures. For example, during the coldest months (January and February) of winter 2010-2011, the average daily minimum air temperatures were 4.1 and $4.6^{\circ} \mathrm{C}$ (Santini et al., 2013) in Corsica. Below $13{ }^{\circ} \mathrm{C}$, the development and growth of citrus is disturbed (Ribeiro and Machado, 2007).

Low temperatures can interfere with photosynthesis and redox homeostasis in cells (Asada, 1999). This disruption of the photosynthetic machinery induces an over-production of reactive oxygen species (ROS) leading to an oxidative stress, one of the most harmful consequences of cold stress (Asada, 2006). The main ROS are $\mathrm{O}_{2}{ }^{-}{ }^{-}$, $\mathrm{H}_{2} \mathrm{O}_{2}$ or the hydroxyl radical $(\mathrm{OH} \cdot)$. They are produced on a regular basis in biological pathways as by-products or signal transducers; however, an excess of ROS can cause oxidative damage to organic molecules like deoxyribonucleic acid (DNA) mutation, protein denaturation and membrane lipid peroxidation (Mittler, 2002; Apel and Hirt, 2004). The latter can lead to changes in the permeability and fluidity of the membrane phospholipid bilayer and can significantly alter cellular integrity. Plants possess antioxidant enzymes (superoxide dismutase (SOD), ascorbate peroxidase (APX), catalase (CAT) and dehydroascorbate reductase (DHAR)) and non-enzymatic antioxidants (ascorbate and proline) for scavenging ROS. This antioxidant system has already been shown to have a crucial role in the cold tolerance of plants (Sabehat et al., 1998).

In this study, we tested whether the use of tetraploid rootstocks can increase the chilling stress tolerance of the citrus graft. The effects of seasonal temperature fluctuations were investigated on common clementine (Citrus clementina Hort. ex Tan) grafted on diploid and tetraploid Carrizo citrange rootstocks.

\section{Materials and methods}

\subsection{Plant material and growth conditions}

The experiment was performed on 40-year-old Clementine trees (Citrus clementina Hort. ex Tan; SRA 63; ICVN 0100059) grafted onto Carrizo citrange rootstock (Citrus sinensis (L.) Obs. $\mathrm{x}$ Poncirus trifoliata (L.) Raf.; ICVN 0110476). Bark samples were collected $\left(1 \mathrm{~cm}^{2}\right.$ area cut from below the bud union) from each single rootstock to determine its ploidy using flow cytometry (Froelicher et al., 2007). In the orchard, 11 tetraploid Carrizo citrange were identified. Four clementine trees grafted onto diploid Carrizo citrange (Citrus sinensis (L.) Obs. x Poncirus trifoliata (L.) Raf) (ICVN 0110476) rootstock (C/2xCC) and four clementine trees grafted onto the respective tetraploid form of the same rootstock $(\mathrm{C} / 4 \mathrm{xCC})$ were selected for investigation. All trees had the same South orientation and were a similar height above ground (about $1.5 \mathrm{~m}$ ). Trees were grown under organic farming conditions in an orchard located in Moriani, Corsica, France $\left(42^{\circ} 23^{\prime} 08^{\prime \prime} \mathrm{N}\right.$ and $09^{\circ}$ $\left.31^{\prime} 47^{\prime \prime} \mathrm{E}\right)$. Measurements and sampling were carried out from October 2015 to May 2016. The same study was also carried out in 2014-2015 and the results obtained were identical (data not shown). The coldest months were January, February and March. We focused on the coldest sunny days of those three months, where the minimum temperature was $-1,0.8$ and $0.9^{\circ} \mathrm{C}$, respectively (Table 1 ). Climatic data were collected throughout the sampling period (Table 1).

Resistance to chilling stress was evaluated through measurement of the main photosynthetic traits (net photosynthesis, stomatal conductance, chlorophyll content and chlorophyll $a$ fluorescence), electrolyte leakage, starch levels, oxidative status (malondialdehyde, hydrogen peroxide); the contribution of the antioxidant system was assessed by enzymatic (scavenging and recycling enzymes) and non-enzymatic assays (ascorbate, proline). For each physiological measurement, 3 mature leaves per tree and per genotype were used (12 replicates). Leaves were selected on 1-year branches subjected to the same light exposure (East, Southeast). Each parameter was measured between 9 am and $11 \mathrm{am}$. For biochemical analyses, 4 samples of 20 fully expanded leaves were sampled for each genotype (4 replicates) once a month from October 2015 to May 2016. This sampling was carried out as described in previous studies (Allario et al., 2013; Hussain et al., 2012; Santini et al., 2012) in which four replicates were used for biochemical parameters. Harvested leaves were immediately immersed in liquid nitrogen and then stored at $-80^{\circ} \mathrm{C}$. Before performing biochemical studies, each leaf sample was ground to a fine powder in liquid nitrogen.

\subsection{Measurements of gas exchange and chlorophyll content}

Leaf net photosynthetic rate $\left(P_{\text {net }}\right)$ and stomatal conductance $\left(G_{\mathrm{s}}\right)$ 
Table 1

Meteorological data from October 2015 to May 2016 at the experimental plot.

\begin{tabular}{|c|c|c|c|c|c|c|c|c|}
\hline \multirow[t]{2}{*}{ Sampling period } & \multicolumn{2}{|c|}{ Mean temperature $\left({ }^{\circ} \mathrm{C}\right)$} & \multicolumn{2}{|c|}{ Minimum temperature $\left({ }^{\circ} \mathrm{C}\right)$} & \multicolumn{2}{|c|}{ Maximum temperature $\left({ }^{\circ} \mathrm{C}\right)$} & \multirow{2}{*}{$\begin{array}{l}\text { Average minimum temperature } \\
\left({ }^{\circ} \mathrm{C}\right) \\
{ }^{1} \mathrm{SM}\end{array}$} & \multirow{2}{*}{$\begin{array}{l}\text { Average maximum temperature } \\
\left({ }^{\circ} \mathrm{C}\right) \\
{ }^{1} \mathrm{SM}\end{array}$} \\
\hline & ${ }^{1} \mathrm{SM}$ & ${ }^{2} \mathrm{SD}$ & ${ }^{1} \mathrm{SM}$ & ${ }^{2} \mathrm{SD}$ & ${ }^{1} \mathrm{SM}$ & ${ }^{2} \mathrm{SD}$ & & \\
\hline October & 16.3 & 14.2 & 5.6 & 8.2 & 24.9 & 18.9 & 11.6 & 21.3 \\
\hline November & 15.4 & 13.5 & 0.9 & 8.8 & 22.1 & 20.9 & 8.1 & 18.6 \\
\hline December & 13.8 & 7.8 & 2.4 & 6.1 & 17.7 & 17.1 & 5.1 & 16.6 \\
\hline January & 9.6 & 7.8 & -1 & 3.9 & 20.9 & 9.1 & 4.5 & 15.1 \\
\hline February & 10.6 & 12.2 & 0.8 & 4.2 & 20.4 & 16.2 & 5.4 & 15.7 \\
\hline March & 11.3 & 12 & 0.9 & 9.4 & 18.3 & 14.8 & 6.3 & 15.9 \\
\hline April & 14.1 & 13 & 2.9 & 4.8 & 22.1 & 18.7 & 8.5 & 19.3 \\
\hline May & 16.9 & 16.3 & 5.8 & 14 & 24.7 & 20.9 & 10.9 & 21.9 \\
\hline
\end{tabular}

${ }^{1}$ SM: Sampling months.

2 SD: Sampling days.

were measured using a LI6400 portable photosynthesis system (Li-COR, Lincoln, NE, USA) with the LI6400-40 Leaf Chamber. For measuring $P_{\text {net }}$ and $G_{s}$, airflow rate was set at $500 \mu \mathrm{mol} \mathrm{s}^{-1}$, carbon dioxide concentration $\left(\mathrm{CO}_{2}\right)$ at $380 \mu \mathrm{mol} \mathrm{mol}{ }^{-1}$ and the temperature at $25^{\circ} \mathrm{C}$. Photosynthetic photon flux density (PPFD) was provided by a red-blue light source (6400-02B no. SI-710, Li-Cor, Lincoln) in a gas exchange chamber and was fixed at $1400 \mu \mathrm{mol} \mathrm{m}^{-2} \mathrm{~s}^{-1}$.

The chlorophyll content was measured non-invasively with a Dualex Scientific $+{ }^{\mathrm{TM}}$ meter (FORCE-A, Paris). Values were obtained in Dualex units, convertibles to $\mathrm{g} \mathrm{cm}^{2}$.

\subsection{Measurements of chlorophyll a fluorescence}

Chlorophyll $a$ fluorescence was measured using a Handy PEA fluorometer (Hansatech, Instruments Ltd) with a resolution of $10 \mathrm{~s}$, in a non-destructive and reproducible manner. Before the measurements, each leaf was dark-adapted with a "leafclip" during $30 \mathrm{~min}$. Following the dark adaptation, a bright flash of saturation intensity $\left(10,000 \mu \mathrm{mol} \mathrm{m}^{-2} \mathrm{~s}^{-1}\right)$ was applied on the leaf surface using three light-emitting diodes $(650 \mathrm{~nm})$. Two parameters were measured: the minimal value of chlorophyll $a$ fluorescence $\left(F_{0}\right)$, when all photosystem II (PSII) centers were open (all the primary quinone acceptors "QA" were oxidized) and the maximum fluorescence $\left(F_{\mathrm{m}}\right)$ when all PSII centers were closed (all QA were reduced) after the emission of a saturating flash of light. The variable fluorescence $\left(F_{\mathrm{v}}\right)$ was obtained by subtracting $F_{0}$ from $F_{\mathrm{m}}$. The maximum quantum efficiency of PSII primary photochemistry was calculated as the ratio $F_{\mathrm{v}} / F_{\mathrm{m}} \quad[=$ $\left(F_{\mathrm{m}}-F_{0}\right) / F_{\mathrm{m}}$ ] (Maxwell and Johnson, 2000).

\subsection{Determination of electrolyte leakage}

Efflux of electrolytes was determined according to the protocol of Thiaw (2003). For each tree, three discs of three different fully expanded leaves were cut with a cork borer, rinsed with distilled water and then placed in test tubes containing $10 \mathrm{~mL}$ of distilled water. Test tubes were submerged in a water bath for $2 \mathrm{~h}$ at $45^{\circ} \mathrm{C}$. Solution conductivity (C1) was measured with a conductivity meter (Mettler Toledo Seven2Go) after cooling to room temperature. Conductivity was measured a second time (C2) after placing the samples in the water bath for $1 \mathrm{~h}$ at $100{ }^{\circ} \mathrm{C}$ and then cooled at room temperature. Electrolyte leakage percentage $(\mathrm{FE} \%)$ was calculated with the formula: $\mathrm{FE}(\%)=$ (C1/C2) × 100 (Tripathy et al., 2000).

\subsection{Determination of oxidative stress response}

Ascorbate and antioxidant enzyme assays were performed as described by Santini et al. (2013).

$\mathrm{H}_{2} \mathrm{O}_{2}$ levels were measured with the method described by Zhou et al. (2006), as modified by Santini et al. (2013). $\mathrm{H}_{2} \mathrm{O}_{2}$ was extracted by homogenizing $80 \mathrm{mg}$ of leaf powder with $2.0 \mathrm{~mL}$ of $5 \%$ trichloroacetic acid (TCA) (w:v) and $60 \mathrm{mg}$ of activated charcoal. The homogenate was centrifuged at $5000 \mathrm{~g}$ for $20 \mathrm{~min}$ at $4{ }^{\circ} \mathrm{C}$. The supernatant was collected. Absorbance was determined at a wavelength of $505 \mathrm{~nm}$. The $\mathrm{H}_{2} \mathrm{O}_{2}$ concentration was calculated using a standard curve of $\mathrm{H}_{2} \mathrm{O}_{2}$.

MDA levels were determined using a thiobarbituric acid (TBA) reaction described by Hodges et al. (1999) and modified by Santini et al. (2013). MDA was extracted by homogenizing $80 \mathrm{mg}$ of leaf powder in $2.0 \mathrm{~mL}$ of $80 \%$ ethanol (v:v). Homogenates were centrifuged at $3000 \mathrm{~g}$ for $10 \mathrm{~min}$ at $4{ }^{\circ} \mathrm{C}$. Absorbance was determined at wavelengths of 440,534 and $500 \mathrm{~nm}$ against a blank.

A V-630 spectrophotometer was used for all measurements (Jasco Inc., Tokyo, Japan).

\subsection{Determination of starch content}

Starch content was determined enzymatically using the Megazyme total starch HK assay kit (Megazyme International Ireland Ltd., Co., Wicklow, Ireland) and by following the manufacturer's recommended procedure. Extraction was carried out at $\mathrm{pH} 5.0$ from $100 \mathrm{mg}$ of leaf powder with $200 \mu \mathrm{L}$ of aqueous ethanol $(80 \% \mathrm{v}: \mathrm{v})$ and $3 \mathrm{~mL}$ of thermostable alpha-amylase diluted with $100 \mathrm{mM}$ sodium acetate $(\mathrm{pH}$ 7.5). Samples were incubated in boiling water bath for $6 \mathrm{~min}$ and then in a bath at $50{ }^{\circ} \mathrm{C}$ for $30 \mathrm{~min}$ with $100 \mu \mathrm{L}$ of amyloglucosidase. The full contents were transferred in $100 \mathrm{~mL}$ volumetric flasks and the volume was adjusted with distilled water. Aliquots were centrifuged at $1077 \mathrm{~g}$ for $10 \mathrm{~min}$. The reaction mixture contained $50 \mu \mathrm{L}$ of crude extract, distilled water, $10 \mu \mathrm{L}$ of buffer $(\mathrm{pH} 7.6)$ with sodium azide $(0.02 \% \mathrm{w}: \mathrm{v})$ and $10 \mu \mathrm{L}$ of $\mathrm{NADP}^{+} / \mathrm{ATP}$. Starch content was measured with a spectrophotometer at $340 \mathrm{~nm}$ with hexokinase/glucose-6-phosphate dehydrogenase reagent. Total starch was expressed in $\mathrm{mg} / \mathrm{mg}$ of fresh weight.

\subsection{Determination of proline content}

Proline contents were measured using the ninhydrin reaction described by Bates et al. (1973), with slight modifications. Proline was extracted from $20 \mathrm{mg}$ of leaf powder, suspended in $1 \mathrm{~mL}$ of $100 \mathrm{mM}$ potassium phosphate buffer $(\mathrm{pH} 7.5)$. Homogenates were then centrifuged at $14,000 \mathrm{~g}$ for $15 \mathrm{~min}$ at $4{ }^{\circ} \mathrm{C}$. The reaction mixture contained $400 \mu \mathrm{L}$ of supernatant and $600 \mu \mathrm{L}$ of $1 \%$ ninhydrin (w:v). After $20 \mathrm{~min}$ of incubation at $95{ }^{\circ} \mathrm{C}, 2 \mathrm{~mL}$ of toluene was added to extracted red products and samples were kept at room temperature and protected from light for $3 \mathrm{~h}$. The absorbance of the toluene layer was determined at $520 \mathrm{~nm}$. Proline content was calculated using a standard curve of proline. A V-630 spectrophotometer was used for all measurements (Jasco Inc., Tokyo, Japan). 

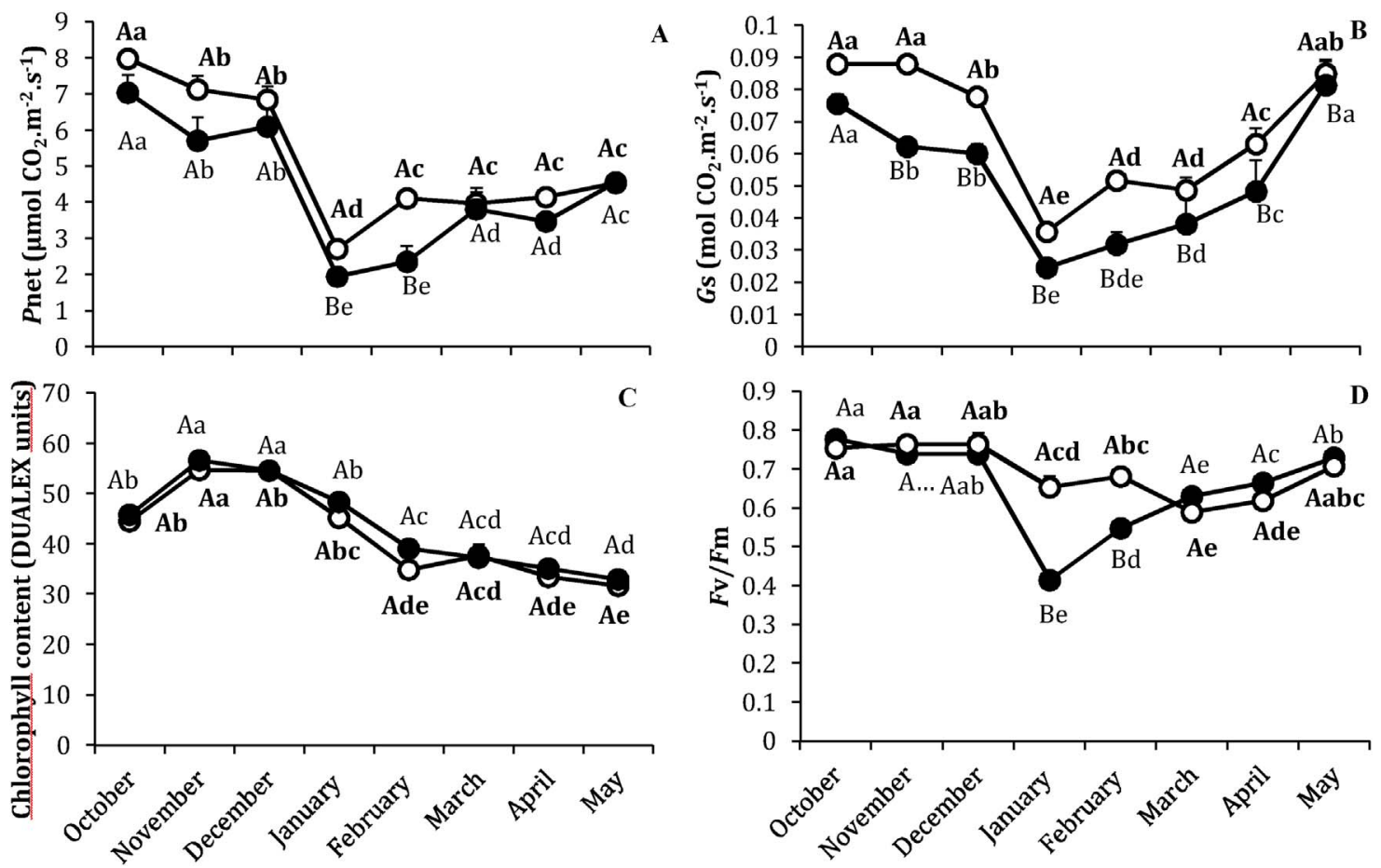

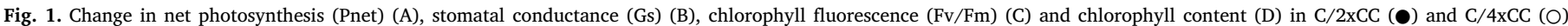

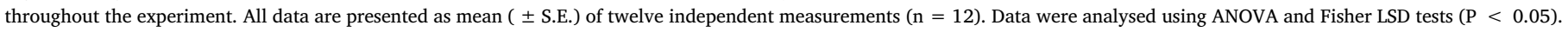

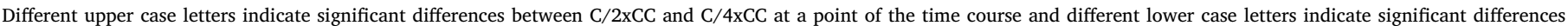
throughout the time course for $\mathrm{C} / 2 \mathrm{xCC}$ or for $\mathrm{C} / 4 \mathrm{xCC}$.

\subsection{Statistical analyses}

The experimental design was a split-plot, with $\mathrm{C} / 4 \mathrm{xCC}$ and $\mathrm{C} / 2 \mathrm{xCC}$ as the main plots and sampling period (months) as the subplot. All statistical measurements were assessed with $\mathrm{R}$ statistical software (http://www.R-project.org). Influence of genotype and sampling period were analysed using two-way ANOVA followed by LSD test at $P<0.05$.

\section{Results}

$P_{\text {net }}$ and $G_{\mathrm{s}}$ decreased from October to January and then increased until May in both $\mathrm{C} / 4 \mathrm{xCC}$ and $\mathrm{C} / 2 \mathrm{xCC}$ (Fig. 1A and B). However, a higher photosynthetic capacity was observed in $\mathrm{C} / 4 \mathrm{xCC}$ than $\mathrm{C} / 2 \mathrm{xCC}$ in January and February for $P_{\text {net }}$, and from November to May for $G_{\mathrm{s}}$. While no significant difference in chlorophyll content was observed between $\mathrm{C} / 4 \mathrm{xCC}$ and $\mathrm{C} / 2 \mathrm{xCC}$ throughout the experiment (Fig. 1C), C/2xCC showed a marked decrease in $F_{\mathrm{v}} / F_{\mathrm{m}}$ compared to $\mathrm{C} / 4 \mathrm{xCC}$ in January and February (Fig. 1D). Also, electrolyte leakage increased significantly from the warm to the cold period in $\mathrm{C} / 2 \mathrm{xCC}$ whereas it did not change significantly in $\mathrm{C} / 4 \mathrm{xCC}$ (Table 2).

Equivalent starch content was measured in $\mathrm{C} / 2 \mathrm{xCC}$ and $\mathrm{C} / 4 \mathrm{xCC}$ at

Table 2

Change in electrolyte leakage between the warm and the cold period.

\begin{tabular}{lll}
\hline & \multicolumn{2}{l}{ Electrolyte leakage (\%) } \\
\cline { 2 - 3 } & Warm period & Cold period \\
\hline $\mathrm{C} / 2 \mathrm{xCC}$ & $20.95 \pm 3.38^{\mathrm{Ab}}$ & $31.18 \pm 2.77^{\mathrm{Aa}}$ \\
$\mathrm{C} / 4 \mathrm{xCC}$ & $21.35 \pm 2.57^{\mathrm{Aa}}$ & $23.64 \pm 1.19^{\mathrm{Ba}}$ \\
\hline
\end{tabular}

All data are presented as mean ( \pm S.E.) of four independent measurements $(n=4)$. Data were analysed using ANOVA and Fisher LSD tests $(\mathrm{P}<0.05)$.

Different upper case letters indicate significant differences between $\mathrm{C} / 2 \mathrm{xCC}$ and $\mathrm{C} / 4 \mathrm{xCC}$ at a point of the time course and different lower case letters indicate significant differences throughout the time course for $\mathrm{C} / 2 \mathrm{xCC}$ or for $\mathrm{C} / 4 \mathrm{xCC}$. each sample point of the experiment, except in March, where $\mathrm{C} / 4 \mathrm{xCC}$ showed a greater accumulation of starch (Fig. 2A). Proline content increased at the beginning of the experiment, and then began to decrease in January in both clementine/rootstocks combinations (Fig. 2B). No difference was observed except in November.

Investigations of leaf $\mathrm{H}_{2} \mathrm{O}_{2}$ contents throughout the experiment revealed no large changes induced by low temperatures (Fig. 3A). Also, no significant difference between $\mathrm{C} / 4 \mathrm{xCC}$ and $\mathrm{C} / 2 \mathrm{xCC}$ was observed except in October.

However, lower wintertime temperatures induced a marked decrease of MDA content from November to March in C/4xCC while it increased from December to February in C/2xCC (Fig. 3B). From March on, MDA contents remained stable until May in $\mathrm{C} / 4 \mathrm{xCC}$ and increased in $\mathrm{C} / 2 \mathrm{xCC}$.

Antioxidant activities (CAT, APX, DHAR and SOD) were monitored throughout the experiment (Fig. 4). During the cold period, C/4xCC had higher CAT, APX and DHAR activities than C/2xCC (Fig. 4A, B and C). $\mathrm{C} / 4 \mathrm{xCC}$ had a greater CAT activity than $\mathrm{C} / 2 \mathrm{xCC}$ from January to May. A significant increase in APX activity was observed in $\mathrm{C} / 4 \mathrm{xCC}$ during some of the coldest months (February and March) (Table 1). Similarly, $\mathrm{C} / 4 \mathrm{xCC}$ had a significantly higher DHAR activity than $\mathrm{C} / 2 \mathrm{xCC}$ in January and February. Finally, SOD activity decreased in both scion/ rootstock combinations with the winter period. No significant difference in SOD activity was observed between $\mathrm{C} / 4 \mathrm{xCC}$ and $\mathrm{C} / 2 \mathrm{xCC}$ (Fig. 4D).

Reduced ascorbate (Asa), total ascorbate (tAsa) and oxidized ascorbate (DHA) contents increased from October to April in both C/ 4xCC and C/2xCC (Fig. 5A B and C) while Asa/DHA ratio decreased during the same period (Fig. 5D). Conversely, in May, Asa, tAsa and DHA contents dropped while Asa/DHA ratio rose. No significant difference was observed between $\mathrm{C} / 4 \mathrm{xCC}$ and $\mathrm{C} / 2 \mathrm{xCC}$ throughout the time period. 

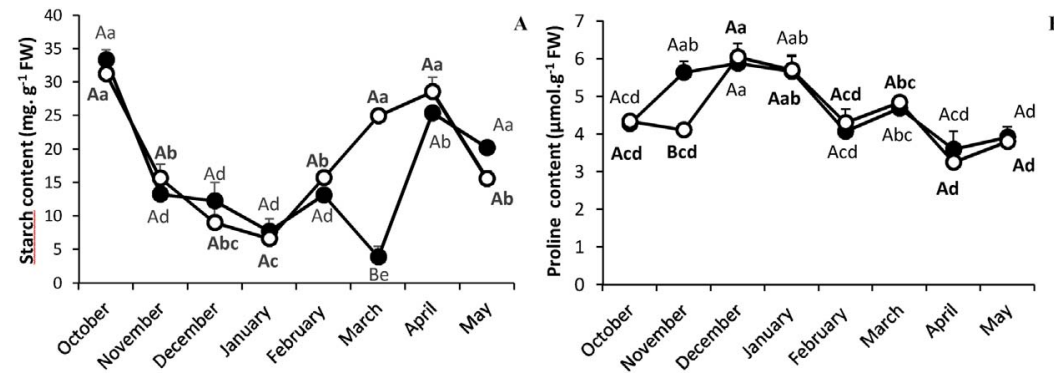

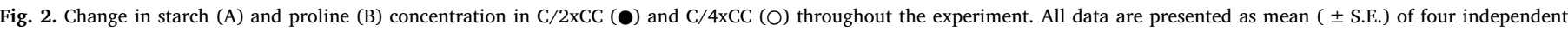

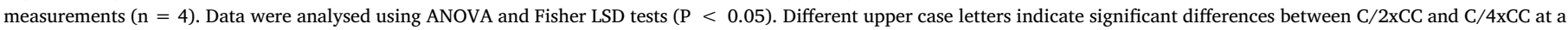
point of the time course and different lower case letters indicate significant differences throughout the time course for $\mathrm{C} / 2 \mathrm{xCC}$ or for $\mathrm{C} / 4 \mathrm{xCC}$.

\section{Discussion}

According to their origin, plants have an optimum temperature for their growth and development. Poncirus trifoliata and Carrizo citrange seedlings are deciduous during winter, which favors cold adaptation. Most citrus trees have an optimum temperature between $22{ }^{\circ} \mathrm{C}$ and $30{ }^{\circ} \mathrm{C}$ (Sun and Ma, 1998). During this experiment, the coldest months were January, February and March. The data were collected during the coldest sunny days of those three months where the minimum temperature was $-1,0.8$ and $0.9^{\circ} \mathrm{C}$, respectively. These low temperatures affected the physiology of the trees.

\subsection{Comparison of physiological and oxidative status of common} clementine grafted onto diploid and tetraploid Carrizo citrange rootstocks during the cold period

When exposed to low temperatures, plant cells are confronted with physiological and biochemical disturbances (Ruelland and Zachowski, 2010). As expected, the decline in $P_{\text {net }}, G_{\mathrm{s}}$ and $F_{\mathrm{v}} / F_{\mathrm{m}}$ was observed during the coldest period for both $\mathrm{C} / 2 \mathrm{xCC}$ and $\mathrm{C} / 4 \mathrm{xCC}$ (Fig. 1A, B and $D)$, as a consequence of the very low temperatures measured for this period (Table 1). In response to low temperatures, plants can maintain their water potential by closing their stomata to prevent water loss by transpiration (Wilkinson et al., 2001). During the time course of the experiment, $P_{\text {net }}$ and $G_{\mathrm{s}}$ appeared to be highly correlated. Thus, the $P_{\text {net }}$ decrease in $\mathrm{C} / 4 \mathrm{xCC}$ and $\mathrm{C} 2 \mathrm{xCC}$ is due to the stomatal closure induced by low temperatures. However, a faster and significant decline for these parameters was observed in $\mathrm{C} / 2 \mathrm{xCC}$ than in $\mathrm{C} / 4 \mathrm{xCC}$, suggesting that tetraploid rootstock maintains higher photosynthetic activities of the scion during the cold period. The lower photoinhibition observed in C/ $4 \mathrm{xCC}$ appears to result in more efficient light use for photosynthesis and therefore $P_{\text {net }}$. This is in agreement with previously reported findings (Brugnoli and Björkman, 1992; Loreto et al., 2009). Indeed, higher maximum quantum yield was also observed in tetraploid citrus genotypes compared to diploid under salt stress or water deficit conditions (Mouhaya et al., 2010; Allario et al., 2013).

We assume that the increased chilling tolerance observed in $\mathrm{C} / 4 \mathrm{xCC}$ is due to an overexpression of genes induced by the tetraploid rootstock. For example, RDM4 that regulates CBF gene expression could have a direct or indirect function during the accumulation of ROS under stress conditions, as indicated by changes in the expression of genes related to ROS (manganese superoxide dismutase I, catalase, microsomal ascorbate peroxidase 5 and cytochrome b561 genes) and the activity of antioxidant enzymes (CAT and SOD), as well as the accumulation of $\mathrm{H}_{2} \mathrm{O}_{2}$ (Chan et al., 2016). Moreover, Dong et al. (2013) also found increased enzymatic activity (SOD and CAT) in transgenic tobacco overexpressing ICE 1 from Vitis amunensis upstream transcription factor (VaICE1) which regulates the transcription of CBFs genes.

Moreover, a study conducted on Valencia scions grafted on diploid and tetraploid Rangpur lime rootstocks showed that tetraploidy changes gene expression in Rangpur lime roots, thereby controlling the adjustment to water stress (Allario et al., 2013). After the coldest months, the recovery of photosynthetic parameters in $\mathrm{C} / 4 \mathrm{xCC}$ and $\mathrm{C} /$ $2 \mathrm{xCC}$ indicates that changes induced by seasonal temperature fluctuations are reversible. The tetraploid rootstock boosts its cold resistance only during the coldest months. Thus, the use of tetraploid rootstocks could be a solution for crops in colder regions.

Chlorophyll is a key biomolecule in the photosynthesis process (Xu et al., 2000) and it is very sensitive to abiotic stress. When investigating $\mathrm{C} / 4 \mathrm{xCC}$ and $\mathrm{C} / 2 \mathrm{xCC}$, the decrease in chlorophyll content due to cold was not significantly different suggesting that tetraploidization of the Carrizo citrange rootstock does not confer protection against chlorophyll damage. However, many studies have shown a lower decrease in chlorophyll content suggesting a more stable photosynthetic system in tetraploid plants under stress conditions. For example, a smaller decrease in chlorophyll content was observed in tetraploid rice under water stress conditions (Yang et al., 2014) and turnip greens subjected to high salt stress (Meng et al., 2012) than in their respective diploid. These results can be explained by the large differentiation observed
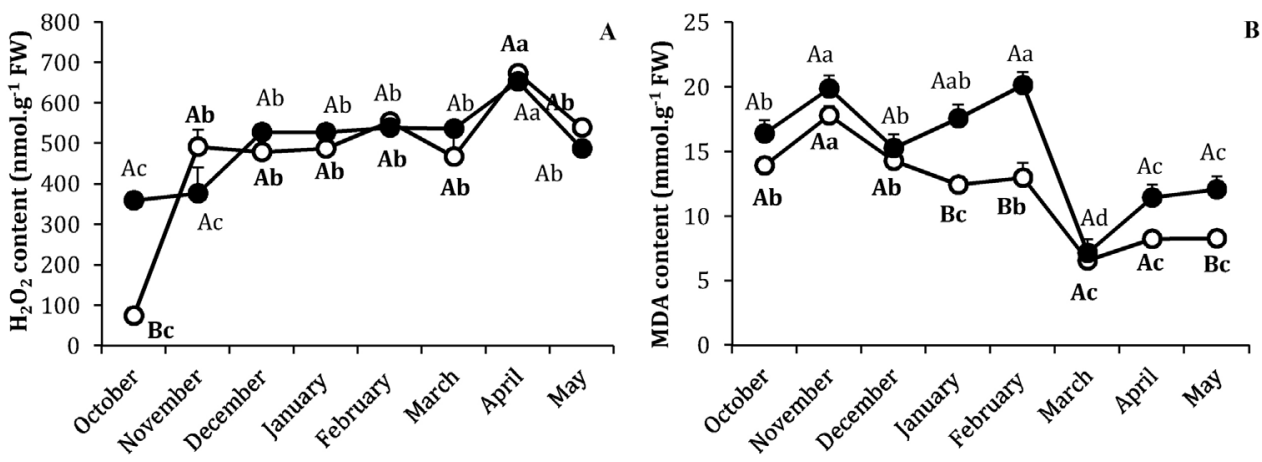

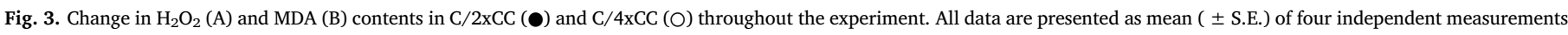

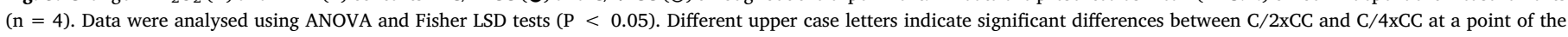
time course and different lower case letters indicate significant differences throughout the time course for $\mathrm{C} / 2 \mathrm{xCC}$ or for $\mathrm{C} / 4 \mathrm{xCC}$. 

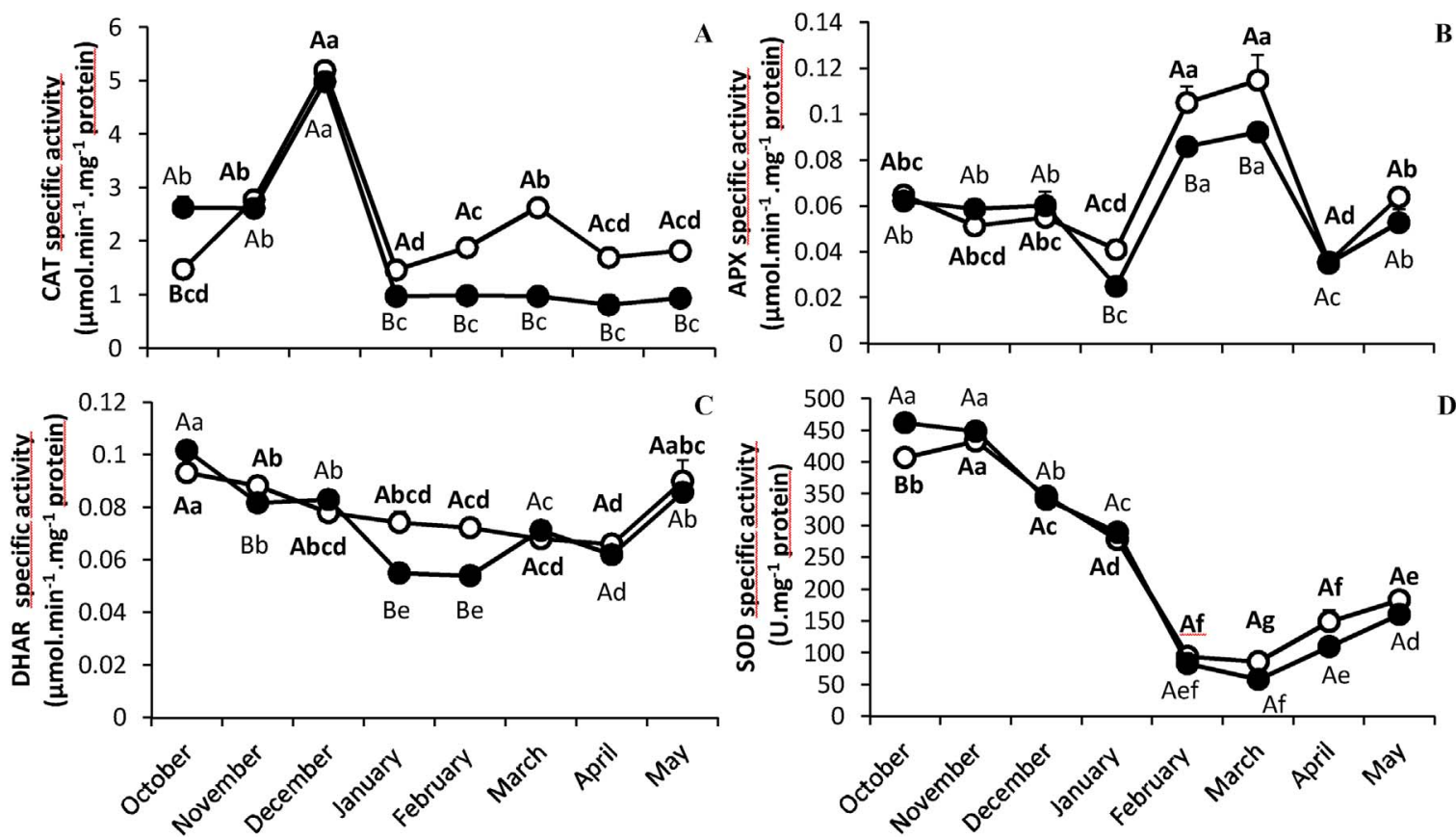

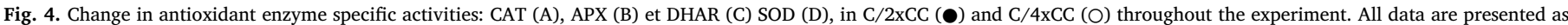

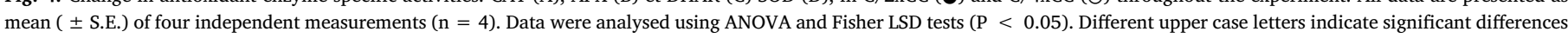
between $\mathrm{C} / 2 \mathrm{xCC}$ and $\mathrm{C} / 4 \mathrm{xCC}$ at a point of the time course and different lower case letters indicate significant differences throughout the time course for $\mathrm{C} / 2 \mathrm{xCC}$ or for $\mathrm{C} / 4 \mathrm{xCC}$.

between diploid and tetraploid (Mouhaya et al., 2010; Allario et al., 2011) leading to better adaptation.

From October to February, leaf starch contents were similar in C/ $2 \times C C$ and $\mathrm{C} / 4 \mathrm{xCC}$. Cold-sensitive plants that change their rates of starch metabolism would indicate a more rapid degradation of starch compared to the rate of photosynthesis (Hodges et al., 1997). A faster accumulation of starch starting in February was found in C/4xCC, while it increased only after March in C/2xCC (Fig. 2A); this suggests an earlier response to increased temperatures in $\mathrm{C} / 4 \mathrm{xCC}$. In that study, tetraploid rootstocks react to photosynthetic sink limitations by increasing starch synthesis. The increase of photosynthesis in February in $\mathrm{C} / 4 \mathrm{xCC}$ and its stabilization in the next months could explain starch accumulation during this period. Indeed, during the warm period, leaf starch and sugar contents were found to be much higher in Clementine
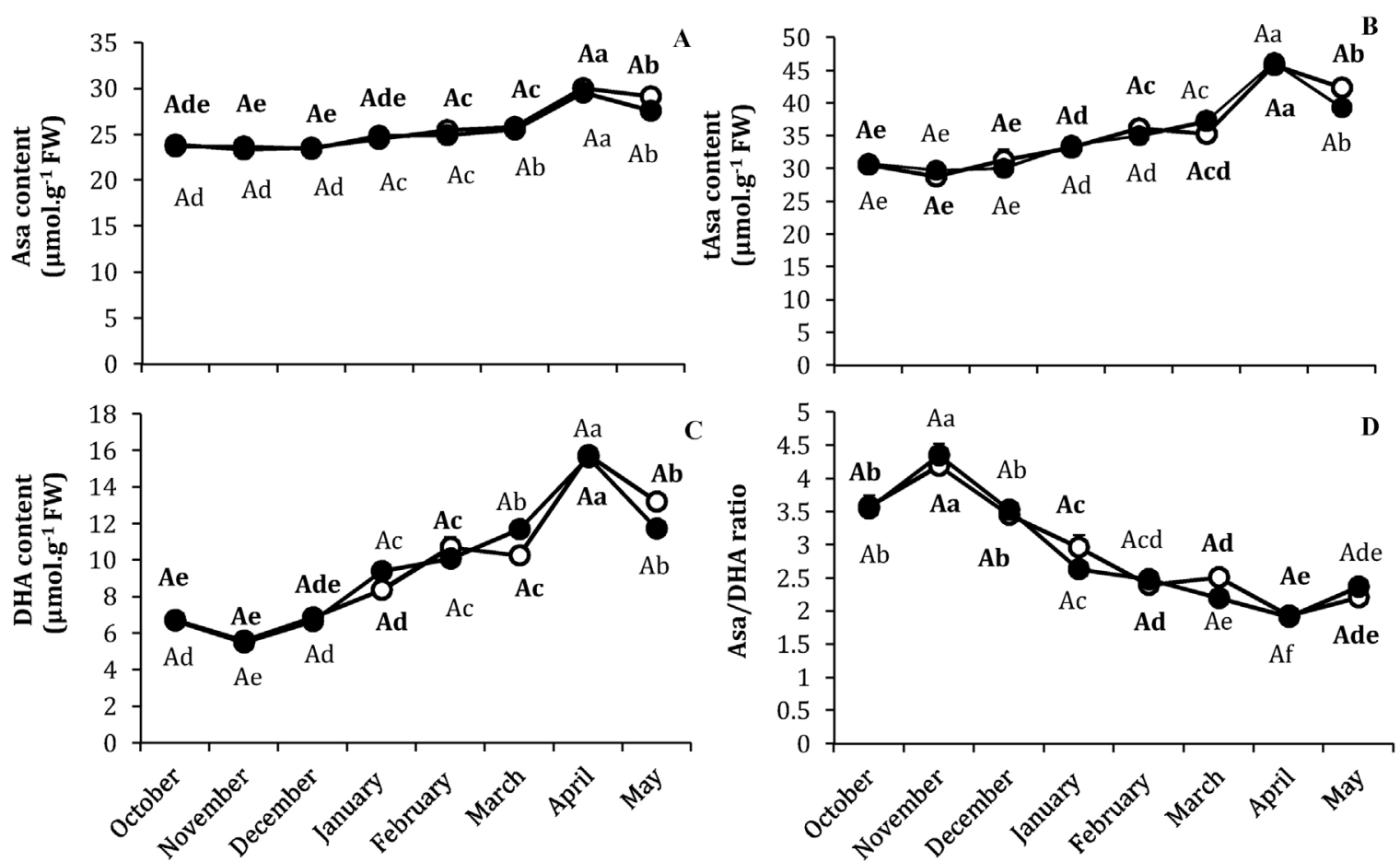

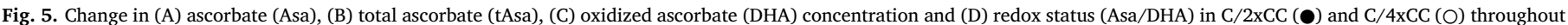

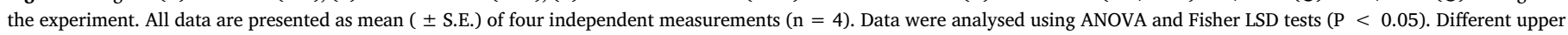

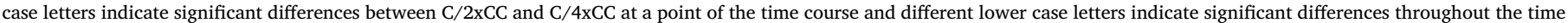
course for $\mathrm{C} / 2 \mathrm{xCC}$ or for $\mathrm{C} / 4 \mathrm{xCC}$. 
grafted onto tetraploid Poncirus rootstocks than onto diploid Poncirus (Hussain et al., 2012).

The increase in $\mathrm{H}_{2} \mathrm{O}_{2}$ and MDA due to environmental stress is commonly used as oxidation indicators. In $\mathrm{C} / 4 \mathrm{xCC}$, the lowest accumulation of MDA and maintenance of $\mathrm{H}_{2} \mathrm{O}_{2}$ levels from January to March would suggest that use of a tetraploid rootstock increases the performance of the antioxidant system and therefore prevents the accumulation of these toxic compounds in the scion leaves during cold periods (Fig. 2A and B). These results are consistent with greater sensitivity of the photosynthetic system observed in C/2xCC. In the literature, similar results were observed in tetraploid plants. For example, a greater accumulation of MDA was found in "Dez orange" (Shafieizargar et al., 2013) and honeysuckle (Li et al., 2009) diploid compared to their tetraploid counterparts subjected to salt stress. This finding indicates that tetraploidization can improve resistance to abiotic stress and thus to oxidative stress.

The accumulation of MDA during the cold period in $\mathrm{C} / 2 \mathrm{xCC}$ is supported by the increase of electrolyte leakage, whereas electrolyte leakage did not increase in $\mathrm{C} / 4 \mathrm{xCC}$ (Table 2). The increased electrolyte leakage and MDA content during cold period in $\mathrm{C} / 2 \mathrm{xCC}$ could indicate cell membrane damage due to lipid peroxidation and thus larger changes in biophysical plant properties at low temperatures. These findings are also consistent with the lower $F_{\mathrm{v}} / F_{\mathrm{m}}$ values observed in $\mathrm{C} /$ $2 x C C$. Studies on cucumber and watermelon have shown that grafting onto cold tolerant rootstocks might reduce the degree of lipid peroxidation and electrolyte leakage induced by cold stress (Gao et al., 2008).

\subsection{Could antioxidant systems explain the better chilling resistance of} leaves from clementines grafted on tetraploid rootstocks compared to diploid ones?

Plant tolerance to oxidative damage may be associated with their ability to eliminate ROS. The antioxidant mechanisms include detoxification enzymes such as SOD, CAT, APX (Huang and Guo, 2005; Almeselmani et al., 2006). In C/4xCC, an increase in CAT and APX activities (Fig. 4A and B) was found from January to March, while their activities remained stable or increased to a lesser extent, respectively, in $\mathrm{C} / 2 \mathrm{xCC}$. This could explain the lower cell damage in $\mathrm{C} / 4 \mathrm{xCC}$. On the whole, tetraploidization of the Carrizo citrange rootstock seems to confer protection against oxidative damage to the scion. The enzymatic response in the scion leaves is dependent upon signalling regulated by rootstocks as suggested by Hippler et al. (2016). This indicates that the communication mechanisms between the scion and rootstock are complex and little is known about them in the literature.

Some studies have highlighted a drop in antioxidant enzyme activities in cold sensitive plants while cold tolerant plants overexpressed genes encoding detoxification enzymes such as SOD, CAT or APX (Mutlu et al., 2013; Xu et al., 2013). A rise in detoxification enzyme activity was often observed in non-grafted tetraploid plants under numerous abiotic stress conditions. For example, in tetraploid Acacia subjected to salt stress (Meng et al., 2016) and in tetraploid wild yam exposed to high temperatures (Zhang et al., 2010), higher enzymatic activity (CAT and APX) and lower concentrations of oxidation indicators (MDA and $\mathrm{H}_{2} \mathrm{O}_{2}$ ) were found compared to their diploid counterparts. An increase in SOD activity was also observed in tetraploid varieties of chrysanthemums (Liu et al., 2011) and in Acacia (Meng et al., 2012) subjected to water and salt stress, respectively, but not in their respective diploid. In addition, a study of two citrus tetraploid rootstocks (Willow leaf mandarin and Cleopatra mandarin) found higher constitutive levels of antioxidant enzymes than their respective diploids during salt stress (Podda et al., 2013).

Another possible reason for increased activity of the antioxidant enzyme system of a scion grafted on a rootstock could be the increased intake of abscisic acid (ABA) and cytokine root to shoot (Schwarz et al., 2010). Indeed, few studies have shown that detoxification enzymes can be up-regulated by phytohormones such as ABA and cytokinins (Jiang and Zhang, 2002; Wang et al., 2003) mainly produced in roots and that can regulate the stress response in the aerial part of the plant. Under control conditions, ABA content in the root of Valencia grafted onto tetraploid rootstock was higher than in roots of Valencia grafted onto diploid rootstock (Allario et al., 2013). This was associated with greater expression of stress responsive genes in tetraploid than in diploid roots, including SOD, DHAR, and alternative oxidase.

Whether in $\mathrm{C} / 4 \mathrm{xCC}$ or $\mathrm{C} / 2 \mathrm{xCC}$, the Asa/DHA ratio (Fig. $5 \mathrm{D}$ ) is greater than 1 throughout the sampling period indicating that more reduced forms (Asa) than oxidized forms (DHA) of ascorbate are produced. This could enable them to fight effectively against oxidative stress over time. The change in Asa/DHA ratio is not always linked to DHAR activity (Fig. 4C). However the Asa/DHA ratio remains above 1, indicating sufficient DHAR activity and/or de novo ascorbate synthesis. Some studies have shown the fundamental role of DHAR in the stress response (Chen et al., 2003; Lee et al., 2007; Mai et al., 2010; Mostofa et al., 2015).

The osmoregulation of proline reduces the water potential of the plant and prevents cold-induced dehydration (Liu et al., 2013). In our study, proline content was not significantly changed no matter the type of rootstock used from the beginning to the end of the sampling period (Fig. 2B). A few studies have shown a greater accumulation of proline in tetraploid plants compared to their diploid counterparts (Li et al., 2009; Shafieizargar et al., 2013).

\section{Conclusion}

A typical response to low temperatures was observed in common clementine grafted onto diploid or tetraploid Carrizo citrange rootstocks. Smaller decrease in photosynthetic capacity, lower levels of MDA, less electrolyte leakage and higher specific activities of CAT, APX and DHAR were observed in trees grafted onto tetraploid Carrizo citrange rootstocks during cold months (mainly January and February). These results show that tetraploid Citrange Carrizo rootstock improves the cold tolerance of the scions. To confirm the relevance of Citrange Carrizo tetraploid rootstock, it would be interesting to study how they impact production and fruit quality of the scion.

\section{Disclosures}

The authors have no conflicts of interest to declare.

\section{Acknowledgements}

Julie Oustric was subsidized by the "Collectivité Territoriale de Corse" (CTC). This work was supported by French CTPS project "AAP12n 3/C2012-01" and by the French Ministry of Agriculture. We are grateful to Patrick Berghman for allowing us to study trees in his organic citrus orchard.

\section{References}

Ahn, S.J., Im, Y.J., Chung, G.C., Cho, B.H., Suh, S.R., 1999. Physiological responses of grafted-cucumber leaves and rootstock roots affected by low root temperature. Sci. Hortic. 81, 397-408.

Aleza, P., Froelicher, Y., Schwarz, S., Agustí, M., Hernández, M., Juárez, J., Luro, F., Morillon, R., Navarro, L., Ollitrault, P., 2011. Tetraploidization events by chromosome doubling of nucellar cells are frequent in apomictic citrus and are dependent on genotype and environment. Ann. Bot. 108, 37-50.

Allario, T., Brumos, J., Colmenero-Flores, J.M., Tadeo, F., Froelicher, Y., Talon, M., Navarro, L., Ollitrault, P., Morillon, R., 2011. Large changes in anatomy and physiology between diploid Rangpur lime (Citrus limonia) and its autotetraploid are not associated with large changes in leaf gene expression. J. Exp. Bot. 62, 2507-2519.

Allario, T., Brumos, J., Colmenero-Flores, J.M., Iglesias, D.J., Pina, J.A., Navarro, L., Talon, M., Ollitrault, P., Morillon, R., 2013. Tetraploid Rangpur lime rootstock increases drought tolerance via enhanced constitutive root abscisic acid production. Plant Cell Environ. 36, 856-868.

Almeselmani, M., Deshmukh, P.S., Sairam, R.K., Kushwaha, S.R., Singh, T.P., 2006. Protective role of antioxidant enzymes under high temperature stress. Plant Sci. 171, 382-388.

Apel, K., Hirt, H., 2004. Reactive oxygen species: metabolism, oxidative stress, and signal 
transduction. Annu. Rev. Plant Biol. 55, 373-399.

Asada, K., 1999. The water-water cycle in chloroplasts: scavenging of active oxygens and dissipation of excess photons. Annu. Rev. Plant Biol. 50, 601-639.

Asada, K., 2006. Production and scavenging of reactive oxygen species in chloroplasts and their functions. Plant Physiol. 141, 391-396.

Bates, L.S., Waldren, R.P., Teare, I.D., 1973. Rapid determination of free proline for water-stress studies. Plant Soil 39, 205-207.

Brochmann, C., Brysting, A.K., Alsos, I.G., Borgen, L., Grundt, H.H., Scheen, A.-C., Elven, R., 2004. Polyploidy in arctic plants. Biol. J. Linn. Soc. 82, 521-536.

Brugnoli, E., Björkman, O., 1992. Chloroplast movements in leaves: influence on chlorophyll fluorescence and measurements of light-induced absorbance changes related to $\Delta \mathrm{pH}$ and zeaxanthin formation. Photosynth. Res. 32, 23-35.

Cameron, J., Frost, H.B., 1968. Genetics, breeding and nucellar embryony. The Citrus Industry 2. pp. 325-370.

Chan, Z., Wang, Y., Cao, M., Gong, Y., Mu, Z., Wang, H., Hu, Y., Deng, X., He, X.-J., Zhu, J.-K., 2016. RDM4 modulates cold stress resistance in Arabidopsis partially through the CBF-mediated pathway. New Phytol. 209, 1527-1539.

Chen, Z., Young, T.E., Ling, J., Chang, S.-C., Gallie, D.R., 2003. Increasing vitamin C content of plants through enhanced ascorbate recycling. Proc. Natl. Acad. Sci. U. S. A. $100,3525-3530$.

Chen, Z.J., 2007. Genetic and epigenetic mechanisms for gene expression and phenotypic variation in plant polyploids. Annu. Rev. Plant Biol. 58, 377.

Dong, C., Zhang, Z., Ren, J., Qin, Y., Huang, J., Wang, Y., Cai, B., Wang, B., Tao, J., 2013. Stress-responsive gene ICE1 from Vitis amurensis increases cold tolerance in tobacco. Plant Physiol. Biochem. 71, 212-217.

Froelicher, Y., Bassene, J.B., Jedidi-Neji, E., Dambier, D., Morillon, R., Bernardini, G., Costantino, G., Ollitrault, P., 2007. Induced parthenogenesis in mandarin for haploid production: induction procedures and genetic analysis of plantlets. Plant Cell Rep. 26, 937-944.

Gao, Q.H., Xu, K., Wang, X.F., Wu, Y., 2008. Effect of grafting on cold tolerance in eggplant seedlings. Acta Hortic. 771, 167-174.

Hippler, F.W.R., Cipriano, D.O., Boaretto, R.M., Quaggio, J.A., Gaziola, S.A., Azevedo, R.A., Mattos-Jr, D., 2016. Citrus rootstocks regulate the nutritional status and antioxidant system of trees under copper stress. Environ. Exp. Bot. 130, 42-52.

Hodges, D.M., Andrews, C.J., Johnson, D.A., Hamilton, R.I., 1997. Antioxidant enzyme responses to chilling stress in differentially sensitive inbred maize lines. J. Exp. Bot. 48, 1105-1113.

Hodges, D.M., DeLong, J.M., Forney, C.F., Prange, R.K., 1999. Improving the thiobarbituric acid-reactive-substances assay for estimating lipid peroxidation in plant tissues containing anthocyanin and other interfering compounds. Planta 207, 604-611.

Huang, M., Guo, Z., 2005. Responses of antioxidative system to chilling stress in two rice cultivars differing in sensitivity. Biol. Plant. 49, 81-84.

Huang, X.-S., Zhang, Q., Zhu, D., Fu, X., Wang, M., Zhang, Q., Moriguchi, T., Liu, J.-H., 2015. ICE1 of Poncirus trifoliata functions in cold tolerance by modulating polyamine levels through interacting with arginine decarboxylase. J. Exp. Bot. 138.

Hussain, S., Curk, F., Dhuique-Mayer, C., Urban, L., Ollitrault, P., Luro, F., Morillon, R., 2012. Autotetraploid trifoliate orange (Poncirus trifoliata) rootstocks do not impact clementine quality but reduce fruit yields and highly modify rootstock/scion physiology. Sci. Hort. 134, 100-107.

Jiang, M., Zhang, J., 2002. Role of abscisic acid in water stress-induced antioxidant defence in leaves of maize seedlings. Free Radic. Res. 36, 1001-1015.

Kramer, P.J., 1940. Root resistance as a cause of decreased water absorption by plants at low temperatures. Plant Physiol. 15, 63.

Krug, C.A., 1943. Chromosome numbers in the subfamily Aurantioideae with special reference to the genus Citrus. Bot. Gaz. 602-611.

Lee, Y.-P., Kim, S.-H., Bang, J.-W., Lee, H.-S., Kwak, S.-S., Kwon, S.-Y., 2007. Enhanced tolerance to oxidative stress in transgenic tobacco plants expressing three antioxidant enzymes in chloroplasts. Plant Cell Rep. 26, 591-598.

Levin, D.A., 1983. Polyploidy and novelty in flowering plants. Am. Nat. 1-25.

Li, W.-D., Biswas, D.K., Xu, H., Xu, C.-Q., Wang, X.-Z., Liu, J.-K., Jiang, G.-M., 2009. Photosynthetic responses to chromosome doubling in relation to leaf anatomy in Lonicera japonica subjected to water stress. Funct. Plant Biol. 36, 783-792.

Liu, C., Zhao, L., Yu, G., 2011. The dominant glutamic acid metabolic flux to produce $\gamma$ amino butyric acid over proline in Nicotiana tabacum leaves under water stress relates to its significant role in antioxidant activity. J. Integr. Plant Biol. 53, 608-618.

Liu, W., Yu, K., He, T., Li, F., Zhang, D., Liu, J., 2013. The low temperature induced physiological responses of Avena nuda L., a cold-tolerant plant species. Sci. World J. 2013.

Loreto, F., Tsonev, T., Centritto, M., 2009. The impact of blue light on leaf mesophyll conductance. J. Exp. Bot. 60, 2283-2290.

Mai, J., Herbette, S., Vandame, M., Cavaloc, E., Julien, J.-L., Ameglio, T., Roeckel-Drevet, P., 2010. Contrasting strategies to cope with chilling stress among clones of a tropical tree, Hevea brasiliensis. Tree Physiol. 30, 1391-1402.

Masterson, J., 1994. Stomatal size in fossil plants: evidence for polyploidy in majority of angiosperms. Science 264, 421-423.

Maxwell, K., Johnson, G.N., 2000. Chlorophyll fluorescence-a practical guide. J. Exp. Bot. 51, 659-668.

McElhaney, R.N., De Gier, J., Van der Neut-Kok, E.C.M., 1973. The effect of alterations in fatty acid composition and cholesterol content on the nonelectrolyte permeability of Acholeplasma laidlawii B cells and derived liposomes. Biochim. Biophys. Acta (BBA)-Biomembr. 298, 500-512.

Meng, F., Pang, H., Huang, F., Liu, L., Wang, Y., 2012. Tetraploid black locust (Robinia pseudoacacia L.) Increased salt tolerance by activation of the antioxidant system. Biotechnol. Biotechnol. Equip. 26, 3351-3358.

Meng, F., Luo, Q., Wang, Q., Zhang, X., Oi, Z., Xu, F., Lei, X., Cao, Y., Chow, W.S., Sun, G., 2016. Physiological and proteomic responses to salt stress in chloroplasts of diploid and tetraploid black locust (Robinia pseudoacacia L.). Sci. Rep. 6.
Mittler, R., 2002. Oxidative stress, antioxidants and stress tolerance. Trends Plant Sci. 7 , $405-410$.

Mostofa, M.G., Hossain, M.A., Fujita, M., Tran, L.-S.P., 2015. Physiological and biochemical mechanisms associated with trehalose-induced copper-stress tolerance in rice. Sci. Rep. 5 .

Mouhaya, W., Allario, T., Brumos, J., Andrés, F., Froelicher, Y., Luro, F., Talon, M., Ollitrault, P., Morillon, R., 2010. Sensitivity to high salinity in tetraploid citrus seedlings increases with water availability and correlates with expression of candidate genes. Funct. Plant Biol. 37, 674-685.

Mutlu, S., Karadağoğlu, Ö., Atici, Ö., Nalbantoğlu, B., 2013. Protective role of salicylic acid applied before cold stress on antioxidative system and protein patterns in barley apoplast. Biol. Plant. 57, 507-513.

Pérez-Clemente, R.M., Montoliu, A., Zandalinas, S.I., de Ollas, C., Gomez-Cadenas, A., 2012. Carrizo citrange plants do not require the presence of roots to modulate the response to osmotic stress. Sci. World J. 2012.

Podda, A., Checcucci, G., Mouhaya, W., Centeno, D., Rofidal, V., Del Carratore, R., Luro, F., Morillon, R., Ollitrault, P., Maserti, B.E., 2013. Salt-stress induced changes in the leaf proteome of diploid and tetraploid mandarins with contrasting $\mathrm{Na}^{+}$and $\mathrm{Cl}$ accumulation behaviour. J. Plant Physiol. 170, 1101-1112.

Ribeiro, R.V., Machado, E.C., 2007. Some aspects of citrus ecophysiology in subtropical climates: re-visiting photosynthesis under natural conditions. Braz. J. Plant Physiol. 19, 393-411.

Ruelland, E., Zachowski, A., 2010. How plants sense temperature. Environ. Exp. Bot. 69, 225-232.

Ruiz, M., Quiñones, A., Martínez-Alcántara, B., Aleza, P., Morillon, R., Navarro, L., PrimoMillo, E., Martínez-Cuenca, M.-R., 2016a. Effects of salinity on diploid (2x) and doubled diploid (4x) Citrus macrophylla genotypes. Sci. Hort. 207, 33-40.

Ruiz, M., Quiñones, A., Martínez-Alcántara, B., Aleza, P., Morillon, R., Navarro, L., PrimoMillo, E., Martínez-Cuenca, M.-R., 2016b. Tetraploidy enhances boron-excess tolerance in carrizo citrange (Citrus sinensis L. Osb; Poncirus trifoliata L. Raf.). Front Plant Sci. 7.

Ruiz, M., Quiñones, A., Martínez- Cuenca, M.-R., Aleza, P., Morillon, R., Navarro, L., Primo-Millo, E., Martinez Alcantara, B., 2016c. Tetraploidy improves salinity tolerance in Carrizo citrange seedlings (Citrus sinensis L. Osb. x Poncirus trifoliata L. Raf.). J. Plant Physiol. 205, 1-10.

Sabehat, A., Lurie, S., Weiss, D., 1998. Expression of small heat-shock proteins at low temperatures a possible role in protecting against chilling injuries. Plant Physiol. 117, 651-658.

Saleh, B., Allario, T., Dambier, D., Ollitrault, P., Morillon, R., 2008. Tetraploid citrus rootstocks are more tolerant to salt stress than diploid. C. R. Biol. 331, 703-710.

Santini, J., Giannettini, J., Pailly, O., Herbette, S., Ollitrault, P., Berti, L., Luro, F., 2013 Comparison of photosynthesis and antioxidant performance of several Citrus and Fortunella species (Rutaceae) under natural chilling stress. Trees 27, 71-83.

Schwarz, D., Rouphael, Y., Colla, G., Venema, J.H., 2010. Grafting as a tool to improve tolerance of vegetables to abiotic stresses: thermal stress, water stress and organic pollutants. Sci. Hort. 127, 162-171.

Shafieizargar, A., Awang, Y., Juraimi, A.S., Othman, R., 2013. Comparative studies between diploid and tetraploid Dez Orange [Citrus sinensis (L.) Osb.] under salinity stress. Aust. J. Crop Sci. 7, 1436.

Soltis, P.S., Soltis, D.E., 2009. The role of hybridization in plant speciation. Annu. Rev. Plant Biol. 60, 561-588.

Stebbins, G.L., 1947. Types of polyploids: their classification and significance. Adv. Genet. 1, 403-429.

Sun, Z., Ma, X., 1998. Thermostability of plasma membrane in citrus leaves. J. Huazhong (Central China) 18, 375-377 Agricultural University.

Tan, F.-Q., Tu, H., Liang, W.-J., Long, J.-M., Wu, X.-M., Zhang, H.-Y., Guo, W.-W., 2015. Comparative metabolic and transcriptional analysis of a doubled diploid and its diploid citrus rootstock (Citrus junos cv. Ziyang xiangcheng) suggests its potential value for stress resistance improvement. BMC Plant Biol. 15, 89.

Thiaw, S., 2003. Association Between Slow Leaf-electrolyte-leakage Under Heat Stress and Heat Tolerance During Reproductive Development in Cowpea. University of California, Riverside.

Tripathy, J.N., Zhang, J., Robin, S., Nguyen, T.T., Nguyen, H.T., 2000. OTLs for cellmembrane stability mapped in rice (Oryza sativa L.) under drought stress. TAG Theor. Appl. Genet. 100, 1197-1202.

Wang, W., Vinocur, B., Altman, A., 2003. Plant responses to drought, salinity and extreme temperatures: towards genetic engineering for stress tolerance. Planta 218, 1-14.

Wilkinson, S., Clephan, A.L., Davies, W.J., 2001. Rapid low temperature-induced stomatal closure occurs in cold-tolerant Commelina communis leaves but not in cold-sensitive tobacco leaves, via a mechanism that involves apoplastic calcium but not abscisic acid. Plant Physiol. 126, 1566-1578.

Xu, W., Rosenow, D.T., Nguyen, H.T., 2000. Stay green trait in grain sorghum: relationship between visual rating and leaf chlorophyll concentration. Plant Breed. 119, 365-367.

Xu, J., Li, Y., Sun, J., Du, L., Zhang, Y., Yu, Q., Liu, X., 2013. Comparative physiological and proteomic response to abrupt low temperature stress between two winter wheat cultivars differing in low temperature tolerance. Plant Biol. 15, 292-303.

Yang, P.-M., Huang, Q.-C., Qin, G.-Y., Zhao, S.-P., Zhou, J.-G., 2014. Different droughtstress responses in photosynthesis and reactive oxygen metabolism between autotetraploid and diploid rice. Photosynthetica 52, 193-202.

Zhang, X.-Y., Hu, C.-G., Yao, J.-L., 2010. Tetraploidization of diploid Dioscorea results in activation of the antioxidant defense system and increased heat tolerance. J. Plant Physiol. 167, 88-94.

Zhou, B., Wang, J., Guo, Z., Tan, H., Zhu, X., 2006. A simple colorimetric method for determination of hydrogen peroxide in plant tissues. Plant Growth Regul. 49, $113-118$.

Ziegler, L.W., Wolfe, H.S., 2017. Citrus growing in Florida. University of Florida Press, Gainesville, pp. 51-53. 